\section{Why pay more when you can pay less?}

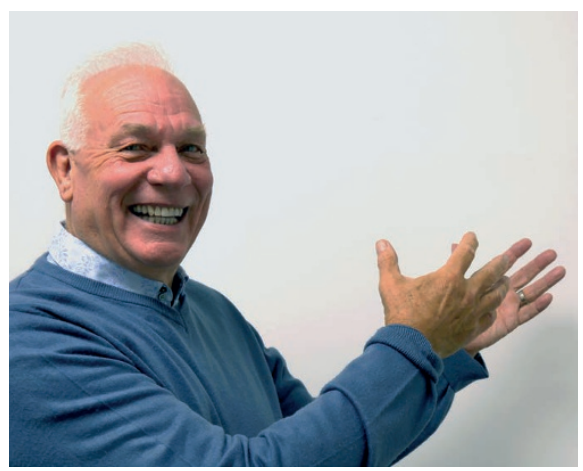

Phil Mathers, the owner of Trycare Ltd has shared his experience of working for 50 years within the dental supply industry.

Mathers, previously managing director of Dentomax, Procare (formerly Baxter Dental) said the truth was that no one ever paid the least and supermarkets were an obvious example where prices, bonuses and special offers changed almost hourly.

'Similarly in dentistry, it's impossible to achieve lowest prices as they also change regularly,' said Mathers. 'Dealers, urged by market forces, customer pressure and competitor activities, move prices all the time. We all do it, simply to compete! However, if you compare the cost of your annual purchases to the cost from other dealers, there is usually very little difference.'

Mathers said he found the pre-occupation of dealers and dentists with pricing disappointing, adding: 'It overshadows the tremendous benefits that a more meaningful dealer relationship can bring. A trusted dealer with a 'can-do' representative and good support team can ensure good prices, on-time deliveries and a wealth of knowledge and product information. This keeps you in touch and helps bring calm and efficiency.

'My advice is measure your prices by what you get for your money. Do you get good prices, good service, good information, and good advice? How comfortable and trusting are you of your supplier?

'I can only speak for Trycare where we believe that great teamwork and helping customers does make a difference and this makes a difference for us as well. Selfish though it is, we realise that doing a fantastic job creates for us a happier environment and more enjoyable working life.'

More information is available by visiting www.trycare.co.uk or by calling 01274885544 .

\title{
All you could need and more
}

When it comes to decontamination in a dental practice, infection control procedures might be faultless, but if the equipment being used is substandard, practitioners are wasting their time because the success of the cleaning, disinfection and sterilisation processes will always dictate their compliance.

Only by investing in quality, reliable products will you be able to ensure consistent sterility and provide a safe, compliant environment for both patients and staff.

The Lisa steriliser from W\&H offers

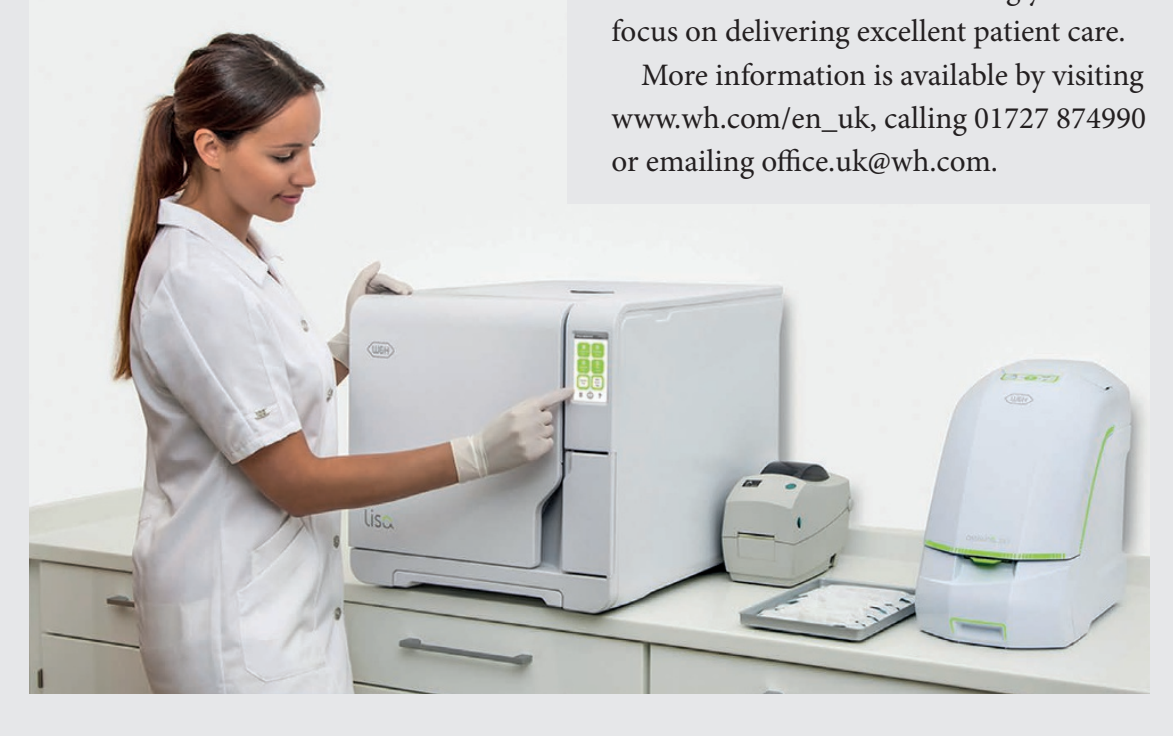

\section{Think differently about waterline disinfection}

For practices looking for an alternative to their waterline disinfection solutions, Nuview offers an extremely efficient and cost effective water-based disinfectant specifically designed for dental unit waterlines.

The Continu disinfectant is capable of removing Legionella and biofilm to European test standards at a cost of less than $£ 2$ per chair per week, making the solution one of the most economic options available to dentists.

It is one of the most compliant too with its CE classification and yellow labelling as per the former National Patient Safety Agency guidelines on colour coding for disinfectant products.

Furthermore, because the product is removed from the system after application, the disinfectant does not go into patients' mouths during treatment, removing any concerns about the taste of the water.

More information is available by calling Nuview on 01453 872266, emailing info@ nuview-ltd.com or by visiting www.nuview.co. everything a practitioner could need and more, with the additional benefits of unrivalled customer service and ongoing technical support.

Amongst other things, Lisa provides an exceptionally fast B cycle of just 30 minutes for an average load of $2 \mathrm{~kg}$ and a 13-minute fast cycle for unwrapped instruments, taking efficiency to the next level.

Along with the intuitive interface, user oriented menu structure with programmable cycle start, and innovative Lisa app for Real Time Remote Monitoring, Lisa saves valuable time and effort allowing you to Mexcellent patient care. www.wh.com/en_uk, calling 01727874990 or emailing office.uk@wh.com.

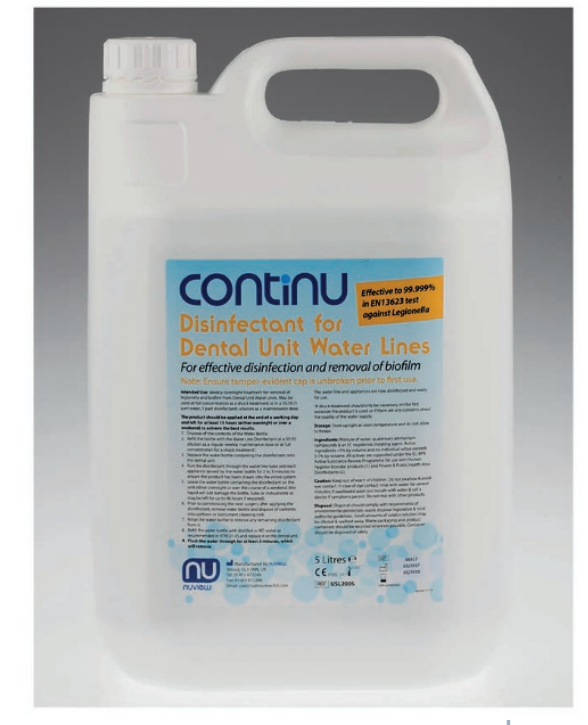

